\title{
The practice of traditional and complementary medicine and factors associated with it among the medical staff in Malaysia
}

\author{
Maihebureti Abuduli ${ }^{1,2^{*}}$, Azam Rahimi ${ }^{1}$, Namaitijiang Maimaiti ${ }^{1}$, Zaleha Md Isa ${ }^{3}$, Syed Mohamed Aljunid ${ }^{4}$ \\ From 7th Postgraduate Forum on Health Systems and Policies \\ Phitsanulok, Thailand. 24-25 June 2013
}

\section{Background}

Traditional and Complementary Medicine (T\&CM) is garnering increasing interest and acceptance among the general population. Different types of T\&CM treatments were increasingly applied and practised by the public but ignorance about T\&CM poses a communication gap between public health and the healthcare profession. The aim of this study was to determine the practice of T\&CM and factors associated with it among medical staff in five selected hospitals in Malaysia.

\section{Materials and methods}

This study employed a cross-sectional design, which was carried out using quantitative and qualitative methods.

\section{Results}

A total of $46.3 \%$ of the medical staff had ever used T\&CM in their life and $32.5 \%$ of them used T\&CM in the last one year, while $48.6 \%$ of the medical staff had ever referred $\mathrm{T} \& \mathrm{CM}$ to their patients or families in their life, and $25.2 \%$ of them referred T\&CM in the last one year. Knowledge regarding $\mathrm{T} \& \mathrm{CM}$ was poor but positive perception regarding education in T\&CM was high. Knowledge regarding T\&CM was significantly higher in Hospital Duchess of Kent (52\%, $\mathrm{p}=0.001)$, among non-Malays $(44 \%, \mathrm{p}=$ $0.047)$, and pharmacists (47.2\%, $\mathrm{p}=0.03)$. Positive perception regarding education in T\&CM among medical staff was higher among females $(88.1 \%, \mathrm{p}=0.002)$ and pharmacists $(93.7 \%, \mathrm{p}<0.001)$. There was no significant association between practice of T\&CM and perception of education in $\mathrm{T} \& \mathrm{CM}$.

\footnotetext{
* Correspondence: arzu0704@gmail.com

'UNU-IIGH, UNU-\|GH Building, UKM Medical Center, Jalan Yaacob Latiff, 56000 Cheras, Kuala Lumpur, Malaysia

Full list of author information is available at the end of the article
}

\section{Conclusions}

Many medical staff had not been exposed to T\&CM education, however most of them had positive perception about health education/training in T\&CM. The provision of information on T\&CM practice and its associated factors among medical staff may help to integrate $T \& C M$ into the mainstream medicine.

\section{Authors' details}

'UNU-IIGH, UNU-IIGH Building, UKM Medical Center, Jalan Yaacob Latiff, 56000 Cheras, Kuala Lumpur, Malaysia. ${ }^{2}$ Xinjiang Uyghur Medical College, Xinjiang, China. ${ }^{3}$ UKM Medical Center, Jalan Yaacob Latiff, 56000 Cheras, Kuala Lumpur, Malaysia. ${ }^{4}$ United Nations University International Institute for Global Health (UNU-IGG), 56000 Cheras, Kuala Lumpur, Malaysia.

Published: 29 January 2014

\section{doi:10.1186/1471-2458-14-S1-022}

Cite this article as: Abuduli et al:: The practice of traditional and complementary medicine and factors associated with it among the medical staff in Malaysia. BMC Public Health 2014 14(Suppl 1):O22.

Submit your next manuscript to BioMed Central and take full advantage of:

- Convenient online submission

- Thorough peer review

- No space constraints or color figure charges

- Immediate publication on acceptance

- Inclusion in PubMed, CAS, Scopus and Google Scholar

- Research which is freely available for redistribution 